\title{
Treatment of Mixed Otitis Externa Using Ceftazidime Powder and Topical Miconazole Versus Topical Miconazole Only
}

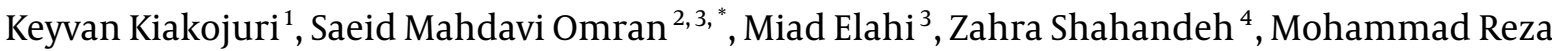 \\ Hasanjani Roushan ${ }^{2}$ and Mojtaba Taghizadeh Armaki $^{3}$ \\ Department of Otolaryngology, Ayatollah Rouhani Teaching Hospital, Babol University of Medical Sciences, Babol, Iran \\ ${ }^{2}$ Infectious Diseases and Tropical Medicine Research Center, Health Research Center, Babol University of Medical Sciences, Babol, Iran \\ ${ }^{3}$ Department of Parasitology and Mycology, School of Medicine, Babol University of Medical Sciences, Babol, Iran \\ ${ }^{4}$ Department of Laboratory Sciences, School of Paramedicine, Babol University of Medical Sciences, Babol, Iran \\ "Corresponding author: Department of Parasitology and Mycology, Infectious Diseases and Tropical Medicine Research Center, Health Research Center, School of Medicine \\ Babol Medical University, Postal Code: 47745-47176, Babol, Iran. Tel/Fax: +98-1132199936, Email: mahdavios@yahoo.co.uk
}

Received 2018 May 28; Revised 2018 September 12; Accepted 2018 September 15.

\begin{abstract}
Background: Otitis externa is an inflammatory in external auditory canal, with the presentation of otalgia, otorrhea, and pruritus. Bacteria and fungi are the most causative agents of the disease. Although several antifungal and antibacterial agents are usually used to treat it, combination therapy plays an important role in good treatment efficacy.

Objectives: According to the problems associated with the treatment of mixed otitis externa, the current study aimed at evaluating the efficacy of ceftazidime powder and topical miconazole (as the case group) versus topical miconazole only (as the control group) to treat mixed otitis externa.

Methods: Seventy-two patients with mixed otitis externa were divided into two groups; the case group was treated with ceftazidime powder and topical miconazole, and the control group was treated only with topical miconazole. Both groups were evaluated after two weeks. The diagnosis of mixed otitis externa was based on signs, symptoms, and the presence of bacterial and fungal elements in direct examination and culture.

Results: Swelling, itching, and canal discharge were observed in $67.7 \%, 64.7 \%$, and $90.3 \%$ of the patients, respectively in the case group, and $47.1 \%, 26.3 \%$ and $93.1 \%$ of the patients, respectively in the control group. Complete resolution of all clinical signs and symptoms occurred in $23(67.6 \%)$ patients in the case group and $11(28.9 \%)$ patients in the control group $(\mathrm{P}=0.001)$. Staphylococcus epidermidis and Pseudomonas aeruginosa were the most common bacteria, and Aspergillus spp. and Candida spp. were the most common fungi identified in the cultures.

Conclusions: According to the complete resolution of clinical signs, the application of ceftazidime powder and topical miconazole was better than topical miconazole to treat mixed otitis externa.
\end{abstract}

Keywords: Mixed Otitis Externa, Miconazole, Ceftazidime

\section{Background}

Otitis externa is an inflammatory process of the external auditory canal, including the auricle, auditory canal, and eardrum $(1,2)$. The presentation of otitis externa includes otalgia, otorrhea, pruritus, aural fullness, hearing impairment, and tinnitus (3). Otalgia and otorrhea are the two most common symptoms of otitis externa at presentation (4-8). The yearly estimated incidence of otitis externa is 8.1 cases per 1000 population (9). Bacteria and fungi are the causative agents $(10,11)$, and the most common bacterial and fungal agents are Pseudomonas spp. and Aspergillus niger, respectively $(12,13)$. Several therapeutic regimens are employed to treat otitis externa (14-17).
A study in the UK on the application of two regimens (neomycin, gramicidin and nystatin versus glycerineichthammol) to treat 64 patients with otitis externa found no statistically significant difference among these regimens in this regard (18). Another study in Spain found no differences in the effectiveness of cycloprox olamine or boric acid to treat otitis externa (19). In a study that compared three different regimens (acetic acid, acetic acid plus steroid therapy, and antibiotics plus steroid therapy), combination therapy with steroids was superior to acetic acid treatment only (20). Despite the high prevalence of otitis externa in Iran, there is no specific treatment protocol for the patients with mixed bacterial-fungal infections.

Thus combination therapy in mixed infective otitis ex- 
terna may be better than only antimicrobial or antifungal treatment. Ceftazidime, a third generation cephalosporin, has more affinity for receptors and makes them as a poor substrate for some $\beta$-lactamases. Its modified structure significantly enhanced its potency against Pseudomonas species (21). It was thought that local application of ceftazidime in combination with miconazole may have better clinical efficacy in mixed infective otitis externa.

\section{Objectives}

The current study aimed at comparing the efficacy of ceftazidime and miconazole versus miconazole alone to treat mixed otitis externa in an Iranian population.

\section{Methods}

\subsection{Ethics Statement}

The current clinical trial was registered in the Iranian Registry of Clinical Trials (Reg. No. IRCT2013102713136N2) (www.irct.ir). Furthermore, the Ethics Committee of Babol University of Medical Sciences, Babol, Iran, approved the design and protocol of the study (code No. 3810). Patients' names and personal information, illnesses and medical information were kept confidential.

\subsection{Study Design and Patients}

The current randomized controlled clinical trial was conducted to compare the efficacy of ceftazidime and miconazole versus miconazole alone to treat mixed otitis externa. Patients attending Ayatollah Rouhani teaching Hospital in Babol from 2015 to 2016 were recruited. The inclusion criteria were clinical manifestations such as discharges, itching, pain, and swelling compatible with mixed otitis externa. The exclusion criteria were chronic otitis media and also isolation of bacteria or fungi from culture. Patients who were immunocompromised were also excluded. The predisposing factors were ear manipulation, poor hygiene, long-term application of broadspectrum antibiotics, and steroids therapy. The patients' demographic features, clinical manifestations, type of therapeutic regimen, and outcomes were recorded. Informed consent was obtained from all the participants. All data in the questionnaires were stored in a safe place and used only for the current study.

\subsection{Sample Size}

The required sample size was estimated 72 cases based on $10 \%$ dropouts due to miconazole regimen failure and $1 \%$ dropout due to failure with the ceftazidime and miconazole regimen.

\subsection{Diagnosis of Mixed Otitis Externa}

The diagnosis of mixed otitis externa was based on the presence of pain, swelling, itching, and otorrhea. The diagnosis of mixed ear infection was based on clinical findings, physician observation, and microbiological tests including direct examinations and culture. Therefore, it is recommended that both organisms should be considered in the treatment protocol of otitis externa.

\subsection{Treatment}

The ear canal was cleaned with $2 \%$ hydrogen peroxide and dried using a swab. It was then flushed with $2 \%$ boric alcohol ( $98 \%$ ethanol and $2 \%$ boric acid). The patients were randomly divided into two groups. The patients in group one $(\mathrm{n}=34)$ received $100 \mathrm{mg}$ of topical miconazole (intervention/case group) administered using a sterile catheter, and $100 \mathrm{mg}$ ceftazidime powder via insufflation. The patients in group two (control, $\mathrm{n}=38$ ) received $100 \mathrm{mg}$ of topical miconazole (control group). Both groups received a single dose of these drugs (22). All the patients were reassessed on the 14th post-treatment day to evaluate clinical signs and symptoms of mixed otitis externa.

\subsection{Statistical Analysis}

All data were analyzed with SPSS version 18.0. The categorical variables were compared using a $t$-test, and the qualitative variables were compared via a Chi-squared test. The selected $\alpha$ and $\beta$ errors were 0.05 and 0.20 , respectively. To compare the efficacy of both regimens, an analysis of variance test was conducted. A value of $\mathrm{P}<0.05$ was considered statistically significant.

\section{Results}

\subsection{Demographical and Clinical Findings}

In total, 72 patients were enrolled in the current study (case group, $\mathrm{n}=34$; control group, $\mathrm{n}=38$ ). The mean age of the patients in the case and control groups was $42.79 \pm$ 19.89 and $45.55 \pm 19.05$ years, respectively $(P=0.55)$. The epidemiological features and clinical manifestations of all the patients are shown in Table 1. Prior to the treatment, the clinical manifestations of the two groups were similar. Post-treatment, itching, and hearing loss were improved in the case group $(\mathrm{P}=0.005$ and $\mathrm{P}=0.022)$. All the clinical signs and symptoms were resolved in $23(67.6 \%)$ patients in the case group as compared with 11 (28.9\%) patients in the control group $(\mathrm{P}=0.001)$. Table 2 provides details on the treatment outcomes of the two groups. 


\begin{tabular}{|c|c|c|c|}
\hline Variable & Case Group, $\mathrm{N}=\mathbf{3 4 ^ { b }}$ & Control Group, $\mathrm{N}=\mathbf{3 8}^{\mathrm{c}}$ & P Value \\
\hline Gender & & & 0.17 \\
\hline Male & $18(52.94)$ & $14(36.84)$ & \\
\hline Female & $16(47.06)$ & $24(63.16)$ & \\
\hline Residence & & & 0.5 \\
\hline Urban & $24(70.59)$ & $24(63.16)$ & \\
\hline Rural & $10(29.41)$ & $14(36.84)$ & \\
\hline \multicolumn{4}{|l|}{ Sign and symptom } \\
\hline Pain & $24(70.59)$ & $19(50)$ & 0.075 \\
\hline Itching & $34(100)$ & $38(100)$ & - \\
\hline Discharge & $31(91.18)$ & $29(76.32)$ & 0.091 \\
\hline Hearing loss & $31(91.18)$ & $36(94.74)$ & 0.55 \\
\hline Swelling & $31(91.18)$ & $26(68.42)$ & 0.18 \\
\hline \multicolumn{4}{|c|}{$\begin{array}{l}\text { a Values are expressed as No. (\%). } \\
\text { b Ceftazidime powder and topical miconazole. } \\
{ }^{c} \text { Topical miconazole. }\end{array}$} \\
\hline \multicolumn{4}{|c|}{ Table 2. Outcome of Treatments in the Study Groups ${ }^{\mathrm{a}}$} \\
\hline Variable & Case Group $^{\text {b }}$ & Control Group ${ }^{c}$ & PValue \\
\hline Pain & $21(61.76)$ & $14(36.84)$ & 0.24 \\
\hline Itching & $22(64.71)$ & $10(26.32)$ & 0.005 \\
\hline Discharge & $28(82.35)$ & $27(71.05)$ & 0.37 \\
\hline Hearing loss & $26(76.47)$ & $21(55.26)$ & 0.022 \\
\hline Swelling & $21(61.76)$ & $16(42.11)$ & 0.2 \\
\hline
\end{tabular}

\subsection{Laboratory Findings}

Direct examination showed that Gram-positive cocci were the most common bacterial agents in both groups, followed by Gram-positive and Gram-negative bacilli in the case group and diphtheroids and Gram-positive bacilli in the control group. True mycelium (55.88\%) and pseudomycelium, with or without yeast cells $(44.12 \%)$, were observed in the case group. In the control group, true mycelium and pseudomycelium were detected in $63.16 \%$ and $36.84 \%$ of patients, respectively. Staphylococcus epidermidis, Pseudomonas spp., and diphtheroids were the most common bacterial causative agents in both groups, according to microbiological analyses (Table 3). Aspergillus spp., particularly A. niger, and Candida spp. were the commonest fungi isolated from cultures in both groups (Table 4).

\section{Discussion}

At present, due to the absence of a specific protocol for mixed otitis externa, the treatment depends on the experience of each clinician and medical resources (23). Previ- ous studies revealed that post-treatment recurrences may be related to the antibiotics used to treat otitis externa (24, 25 ). The current study results showed that a regimen containing both an antimicrobial and antifungal agent was preferable to a fungal agent alone. The results of the current study were consistent with those of other studies (26, 27). A previous study reported that Triadcortyl ${ }^{\circledR}$ (TAC) combination with three antibiotic agents (neomycin, gramicidin, and nystatin) was more effective than glycerineichthammol (GI) solution alone to relief pain in patients with severe acute otitis externa (i e, cases with approximately six months of otitis externa symptoms manifestation) (18).

However in the current study, the average duration of otitis externa was seven months. Previous studies reported that patients with long-term antibacterial therapy are predisposed to the fungal colonization of external ear and concluded that the initial regimen should consist of antifungal therapy $(11,26)$. The current study employed a combination of antibacterial and antifungal agents concurrently and found a high curative rate. Specifically, symptoms of mixed otitis externa were resolved in $67 \%$ of pa- 


\begin{tabular}{|c|c|c|c|}
\hline Bacterial Species & Case Group $^{b}$ & Control Group ${ }^{c}$ & Total \\
\hline Staphylococcus epidermidis & $11(32.36)$ & $19(50)$ & $30(41.66)$ \\
\hline Pseudomonas luteola & 0 & $1(2.63)$ & $1(1.39)$ \\
\hline Pseudomonas aeruginosa & $6(17.65)$ & $5(13.16)$ & $11(15.27)$ \\
\hline Diphtheroids agents & $5(14.71)$ & $4(10.53)$ & $9(12.5)$ \\
\hline Staphylococcus aurous & $2(5.88)$ & $3(7.9)$ & $5(6.94)$ \\
\hline Klebsiella pneumonia & $2(5.88)$ & 0 & $2(2.78)$ \\
\hline Micrococcus spp. & 0 & $2(5.26)$ & $2(2.78)$ \\
\hline Acinetobacter baumannii & $2(5.88)$ & 0 & $2(2.78)$ \\
\hline Gram-negative bacilli (oxidase positive) & $2(5.88)$ & 0 & $2(2.78)$ \\
\hline Enterobacter sakazaki & 0 & $1(2.63)$ & $1(1.39)$ \\
\hline Enterobacter kloake & $1(2.94)$ & $1(2.63)$ & $2(2.78)$ \\
\hline Gram positive bacilli (coagulase negative) & $1(2.94)$ & $1(2.63)$ & $2(2.78)$ \\
\hline Escherichia coli & $1(2.94)$ & 0 & $1(1.39)$ \\
\hline Citrobacter kosery & $1(2.94)$ & 0 & $1(1.39)$ \\
\hline Proteus mirabilis & 0 & $1(2.63)$ & $1(1.39)$ \\
\hline Total & $34(100)$ & $38(100)$ & $72(100)$ \\
\hline
\end{tabular}

${ }^{\text {a }}$ Values are expressed as No. (\%).

${ }^{\mathrm{b}}$ Ceftazidime powder and topical miconazole.

${ }^{\mathrm{c}}$ Topical miconazole.

Table 4. Fungal Species Isolated from Patients With Mixed Otitis Externa ${ }^{\mathrm{a}}$

\begin{tabular}{|c|c|c|c|}
\hline Fungal Species & Case Group $^{\mathbf{b}}$ & Control Group $^{c}$ & Total \\
\hline Aspergillus niger & $9(26.48)$ & $7(18.42)$ & $16(22.22)$ \\
\hline Aspergillus flavus & $2(5.88)$ & 0 & $2(2.78)$ \\
\hline Aspergillus fumigatus & $3(8.82)$ & $2(5.26)$ & $5(6.94)$ \\
\hline Aspergillus sp. & $3(8.82)$ & $11(28.95)$ & $14(19.44)$ \\
\hline Mucor sp. & 0 & $1(2.63)$ & $1(1.39)$ \\
\hline Penicillium sp. & $3(8.82)$ & $3(7.9)$ & $6(8.34)$ \\
\hline Candida sp. & $14(41.18)$ & $14(36.84)$ & $28(38.89)$ \\
\hline Total & $34(100)$ & $38(100)$ & $72(100)$ \\
\hline
\end{tabular}

${ }^{\text {a }}$ Values are expressed as No. (\%).

${ }^{\mathrm{b}}$ Ceftazidime powder and topical miconazole.

c Topical miconazole.

tients treated with combination therapy versus $29 \%$ of patients receiving the single therapy. The curative rate was better than that of reported by Abelardo et al., following the administration of antibiotics and steroids for two weeks (2).

Balen et al., administered single and combination regimens (steroid therapy alone, steroid plus acetic acid, and steroid plus antibiotic) in cases with otitis externa and reported a $40 \%$ cure rate seven days post-treatment with the combination regimens (20). The superior outcomes obtained in the current study may be due to the presence of S. epidermidis and P. aeruginos $a$ as the causative agents in most cases, both of which are commensal bacteria. The causative agents isolated in the current study were consistent with those of the earlier works $(24,28,29)$. In the current study, itching and hearing loss in the external ear canal revolved following combination therapy.

In contrast, in a study conducted in the US, Rosenfeld et al., reported that these symptoms had the same pain improvement following single therapy with a steroid and antimicrobial/steroid combinations (17). The difference may be due to the milder form of otitis externa in the patients in the US study. Mosges et al., reported the resolution of ear canal swelling in $61 \%$ of cases of otitis externa following 
antibiotic and steroid therapy for 10 days (30). The current study achieved a higher response rate using a single dose of ceftazidime powder and topical miconazole in comparison with the control group. However, Mosges et al., reported a higher rate of pain relief (90\%) (30), as compared with $(61.76 \%)$ the current study. It is thought this finding is related to antimicrobial activity of ceftazidime and also the physical effect of its powder; thus, it is proposed that this effect be evaluated with inert powder and the results be compared with non-powder form of the antibiotic. Also, the penetration of antibiotics such as ceftazidime should be measured.

\subsection{Conclusions}

The current study results showed that hearing loss and itching were resolved in more patients treated with ceftazidime powder and topical miconazole than the patients treated with miconazole only. Overall, the efficacy of ceftazidime powder and topical miconazole was better than that of miconazole alone to treat mixed otitis externa.

\section{Acknowledgments}

Authors wish to thank the Vice-Chancellery for Research at Babol University of Medical Sciences for the approval of the study and also for the financial and official support. The authors also thank all the study participants, Dr. Mahmood Hajiahmadi for the statistical analysis, Mrs. Zahra Naderian and Maryam Sadat Shafii for providing laboratory facilities.

\section{Footnotes}

Authors' Contribution: Keyvan Kiakojuri: ear samples collection and the primary design of the study; Saeid Mahdavi Omran: study designed, mycology laboratory tests, writing the manuscript; Mohammad Reza Hasanjani Roushan: editing the manuscript; Zahra Shahandeh, Mojtaba Taghizadeh Armaki, and Miad Elahi: microbiology examinations and planning for another works. The manuscript was written by Saeid Mahdavi Omran and was reviewed and confirmed by all the authors.

Conflict of Interest: Authors declared no conflict of interest.

Funding/Support: The study was financially supported by Babol University of Medical Sciences, Babol, Iran (project number: 9237124).

\section{References}

1. Beers SL, Abramo TJ. Otitis externa review. Pediatr Emerg Care. 2004;20(4):250-6. [PubMed: 15057182].
2. Abelardo E, Pope L, Rajkumar K, Greenwood R, Nunez DA. A doubleblind randomised clinical trial of the treatment of otitis externa using topical steroid alone versus topical steroid-antibiotic therapy. Eur Arch Otorhinolaryngol. 2009;266(1):41-5. doi: 10.1007/s00405-0080712-y. [PubMed: 18560873].

3. Ozcan KM, Ozcan M, Karaarslan A, Karaarslan F. Otomycosis in Turkey: Predisposing factors, aetiology and therapy. J Laryngol Otol. 2003;117(1):39-42. doi: 10.1258/002221503321046621. [PubMed: 12590854].

4. Halpern MT, Palmer CS, Seidlin M. Treatment patterns for otitis externa. J Am Board Fam Pract.1999;12(1):1-7. [PubMed: 10050637].

5. Fasunla J, Ibekwe T, Onakoya P. Otomycosis in western Nigeria. $M y$ coses. 2008;51(1):67-70. doi: 10.1111/j.1439-0507.2007.01441.x. [PubMed: 18076598].

6. Kaur R, Mittal N, Kakkar M, Aggarwal AK, Mathur MD. Otomycosis: A clinicomycologic study. Ear Nose Throat J.2000;79(8):606-9. [PubMed: 10969470].

7. Yilmaz G, Aydin K, Bektas D, Caylan R, Caylan R, Koksal I. Cerebellar abscess and meningitis, caused by Shewanella putrefaciens and Klebsiella pneumoniae, associated with chronic otitis media. J Med Microbiol.2007;56(Pt 11):1558-60. doi: 10.1099/jmm.0.47044-0. [PubMed: 17965359].

8. Paulose KO, Al Khalifa S, Shenoy P, Sharma RK. Mycotic infection of the ear (otomycosis): A prospective study.J Laryngol Otol.1989;103(1):30-5. [PubMed: 2921549].

9. Centers for Disease Control and Prevention (CDC). Estimated burden of acute otitis externa United States, 2003-2007. MMWR Morb Mortal Wkly Rep. 2011;60(19):605-9. [PubMed: 21597452].

10. Mugliston T, O'Donoghue G. Otomycosis: A continuing problem. J Laryngol Otol.1985;99(4):327-33. [PubMed: 4009029].

11. Barati B, Okhovvat SA, Goljanian A, Omrani MR. Otomycosis in central Iran: A clinical and mycological study. Iran Red Crescent Med J. 2011;13(12):873-6. [PubMed: 22737432]. [PubMed Central: PMC3371907].

12. Sander R. Otitis externa: A practical guide to treatment and prevention. Am Fam Physician. 2001;63(5):927-36. 941-2. [PubMed: 11261868].

13. Ninkovic G, Dullo V, Saunders NC. Microbiology of otitis externa in the secondary care in United Kingdom and antimicrobial sensitivity. Auris Nasus Larynx. 2008;35(4):480-4. doi: 10.1016/j.anl.2007.09.013. [PubMed: 18314283].

14. Pabla L, Jindal M, Latif K. The management of otitis externa in UK general practice. Eur Arch Otorhinolaryngol. 2012;269(3):753-6. doi: 10.1007/s00405-011-1687-7. [PubMed: 21761191].

15. Hobson CE, Moy JD, Byers KE, Raz Y, Hirsch BE, McCall AA. Malignant otitis externa: Evolving pathogens and implications for diagnosis and treatment. Otolaryngol Head Neck Surg. 2014;151(1):112-6. doi: 10.1177/0194599814528301. [PubMed: 24675790].

16. Tsikoudas A, Jasser P, England RJ. Are topical antibiotics necessary in the management of otitis externa? Clin Otolaryngol Allied Sci. 2002;27(4):260-2. [PubMed: 12169127].

17. Rosenfeld RM, Singer M, Wasserman JM, Stinnett SS. Systematic review of topical antimicrobial therapy for acute otitis externa. Otolaryngol Head Neck Surg. 2006;134(4 Suppl):S24-48. doi: 10.1016/j.otohns.2006.02.013. [PubMed:16638474].

18. Masood A, Moumoulidis I, Ray S, Chawla O, Panesar J. A randomised controlled trial comparing Triadcortyl with $10 \%$ glycerineichthammol in the initial treatment of severe acute otitis externa. EurArch Otorhinolaryngol.2008;265(8):881-5. doi:10.1007/s00405-0070463-1. [PubMed: 17922130].

19. del Palacio A, Cuetara MS, Lopez-Suso MJ, Amor E, Garau M. Randomized prospective comparative study: Short-term treatment with ciclopiroxolamine (cream and solution) versus boric acid in the treatment of otomycosis. Mycoses. 2002;45(8):317-28. [PubMed: 12572722].

20. Balen FA, Smit WM, Zuithoff NP, Verheij TJ. Clinical efficacy of three common treatments in acute otitis externa in primary care: Randomised controlled trial. BMJ. 2003;327(7425):1201-5. doi: 10.1136/bmj.327.7425.1201. [PubMed: 14630756]. [PubMed Central: PMC274056]. 
21. Zasowski EJ, Rybak JM, Rybak MJ. The beta-lactams strike back: Ceftazidime-avibactam. Pharmacotherapy. 2015;35(8):755-70. doi: 10.1002/phar.1622. [PubMed: 26289307]. [PubMed Central: PMC4545577].

22. Mahdavi Omran S, Yousefzade Z, Khafri S, Taghizadeh-Armaki M, Kiakojuri K. Effect of combination therapy with ceftizoxime and clotrimazole in the treatment of otomycosis. Curr Med Mycol. 2018;4(1):1823. doi: $10.18502 / \mathrm{cmm} .4 .1 .30$. [PubMed: 30186989]. [PubMed Central: PMC6101155].

23. Kaushik V, Malik T, Saeed SR. Interventions for acute otitis externa. Cochrane Database Syst Rev. 2010;(1). CD004740. doi: 10.1002/14651858.CD004740.pub2. [PubMed: 20091565].

24. Martin TJ, Kerschner JE, Flanary VA. Fungal causes of otitis externa and tympanostomy tube otorrhea. Int J Pediatr Otorhinolaryngol. 2005;69(11):1503-8. doi: 10.1016/j.ijporl.2005.04.012. [PubMed: 15927274].

25. Cheffins T, Heal C, Rudolphy S. Acute otitis externa: Management by GPs in North Queensland. Aust J Prim Health. 2009;38(4):262-3. [PubMed: 19350078].
26. Jackman A, Ward R, April M, Bent J. Topical antibiotic induced otomycosis. Int J Pediatr Otorhinolaryngol. 2005;69(6):857-60. doi: 10.1016/j.ijporl.2005.01.022. [PubMed: 15885342].

27. Prasad SC, Kotigadde S, Shekhar M, Thada ND, Prabhu P, D' Souza T, et al. Primary otomycosis in the Indian subcontinent: Predisposing factors, microbiology, and classification. Int J Microbiol. 2014;2014:636493. doi: 10.1155/2014/636493. [PubMed: 24949016]. [PubMed Central: PMC4052204].

28. Cheong CS, Tan LM, Ngo RY. Clinical audit of the microbiology of otorrhoea referred to a tertiary hospital in Singapore. Singapore Med J. 2012;53(4):244-8. [PubMed: 22511046].

29. Shafi M, Ujjan ID. Otomycosis: A clinico-pathological study.J Surg Pakistan. 2016;21(4). doi: 10.21699/jsp.21.4.8.

30. Mosges R, Domrose CM, Loffler J. Topical treatment of acute otitis externa: Clinical comparison of an antibiotics ointment alone or in combination with hydrocortisone acetate. Eur Arch Otorhinolaryngol. 2007;264(9):1087-94. doi: 10.1007/s00405-007-0314-0. [PubMed: 17503066]. 